\title{
Multiparametric flow cytometry analysis of peripheral blood B cell trafficking differences among Epstein-Barr virus infected and uninfected subpopulations
}

\author{
Katerina Zachova a , Petr Kosztyua , Josef Zadrazil ${ }^{b}$, Karel Matousovic, ${ }^{c}$ Karel Vondrak ${ }^{\mathrm{d}}$, Petr Hubacek ${ }^{\mathrm{e}}$, Klara Kostovcikovah, \\ Helena Tlaskalova Hogenovah, Jiri Mestecky ${ }^{\mathrm{f}, \mathrm{gh}}$, Milan Raska ${ }^{\mathrm{a}, \mathrm{g}}$
}

\begin{abstract}
Aims. Epstein-Barr virus (EBV) targets predominantly B cells and these cells could acquire new phenotype characteristics. Here we analyzed whether EBV-infected and -uninfected B cells from healthy subjects differ in proportion of dominant phenotypes, maturation stage, and homing receptors expression.

Methods. EBV-infected and -uninfected cells were identified by flow cytometry using fluorophore-labeled EBV RNAspecific DNA probes combined with fluorophore-labeled antibody to surface lineage markers, integrins, chemokine receptors, and immunoglobulin isotypes, including intracellular ones.

Results. Our results show that the trafficking characteristics of EBER ${ }^{\text {pos }} B$ cells are distinct from EBER ${ }^{\text {neg }} B$ cells with most dominant differences detected for $a 4 \beta 1$ and $a 4 \beta 7$ and CCR5 and CCR7. EBV-positive cells are predominantly memory $\operatorname{lgM}^{+} B$ cells or plasmablasts/plasma cells (PB/PC) positive for lgA or less for lgM. In comparison to uninfected $B$ cells, less EBV-positive $B$ cells express $\alpha 4 \beta 7$ and almost no cells express $a 4 \beta 1$. EBV-positive $B$ cells contained significantly higher proportion of $C \mathrm{CR} 5^{+}$and $\mathrm{CCR} 7^{+}$cells in comparison to EBV-negative cells. In vitro exposure of blood mononuclear cells to pro-inflammatory cytokine IL-6 reduces population of EBV-positive B cell.

Conclusion. Although EBV-infected B cells represent only a minor subpopulation, their atypical functions could contribute in predisposed person to development abnormities such as some autoimmune diseases or tumors. Using multi-parameter flow cytometry we characterized differences in migration of EBV-positive and -negative B cells of various maturation stage and isotype of produced antibodies particularly different targeting to mucosal tissues of gastrointestinal and respiratory tracts.
\end{abstract}

Key words: Epstein-Barr virus, cell trafficking, lgM, IgA, naïve B cells, memory B cells, plasma blast, plasma cell

Received: May 20, 2019; Revised: June 24, 2019; Accepted: June 27, 2019; Available online: October 22, 2019

https://doi.org/10.5507/bp.2019.052

(c) 2020 The Authors; https://creativecommons.org/licenses/by/4.0/

${ }^{a}$ Department of Immunology, Faculty of Medicine and Dentistry, Palacky University Olomouc and University Hospital Olomouc, Czech Republic

${ }^{b}$ Department of Internal Medicine III - Nephrology, Rheumatology and Endocrinology, Palacky University Olomouc and University Hospital Olomouc, Czech Republic

'Department of Internal Medicine, $2^{\text {nd }}$ Faculty Medicine, Charles University in Prague and University Hospital Motol, Prague, Czech Republic ${ }^{d}$ Department of Pediatrics, $2^{\text {nd }}$ Faculty Medicine, Charles University in Prague, Czech Republic

${ }^{e}$ Department of Microbiology, $2^{\text {nd }}$ Faculty Medicine, Charles University in Prague and University Hospital Motol, Prague, Czech Republic fDepartment of Medicine, University of Alabama at Birmingham, Birmingham, Alabama, USA

${ }^{9}$ Department of Microbiology, University of Alabama at Birmingham, Birmingham, Alabama, USA

${ }^{h}$ Laboratory of Cellular and Molecular Immunology, Institute of Microbiology, Czech Academy of Sciences, Prague, Czech Republic Corresponding authors: Milan Raska, e-mail:milan.raska@upol.cz; Jiri Mestecky, e-mail:mestecky@uab.edu

\section{INTRODUCTION}

EBV infection has been reported to be involved in the development of various human diseases of infectious (infectious mononucleosis), malignant (nasopharyngeal carcinoma, Burkitt's lymphoma, Hodgkin lymphoma, and others), and autoimmune (systemic lupus erythematosus, multiple sclerosis, and inflammatory bowel disease) nature ${ }^{1-7}$. EBV infects predominantly B cells but these cells do not express specific surface markers to be distinguished from healthy ones. Combination of in situ hybridization with flow cytometry clearly enables identification of EBVinfected cells in population of thousand to millions of peripheral blood mononuclears. Moreover, it is possible to specify their phenotype, immunoglobulin isotype, and their migration profile by identification of surface-exposed or intracellular molecules such as chemokine receptors, integrins or selectins, surface and intracellular immunoglobulin isotype and lineage-specific markers. Changes in expression of different markers between EBV-infected and healthy cells and changes in their function could help to reveal the etiological aspects of various diseases suspicious of association with EBV infection.

By multicolor flow cytometry phenotyping of EBVpositive and EBV-negative cells based on EBV RNA hybridization and antibody detection of lineage markers CD19, CD27, CD38, CD138, surface and intracellular immunoglobulins IgA, IgG, IgM, IgD, integrins $\alpha 4 \beta 1$ and $\alpha 4 \beta 7$, L-selectin and chemokine receptors CCR5, CCR7, CCR9, and CCR 10 the differences in phenotypes, surface 
and intracellular isotypes and migration characteristics were analyzed.

Because inflammatory stimulation of EBV-infected cells has been proposed to play a role in the EBVassociated diseases, peripheral blood mononuclear cells (PBMC) were exposed in vitro to IL-6, that is known as an effective B cell activator ${ }^{8-10}$, to analyze whether stimulation of EBV-infected B cells change their behavior, phenotypes and immunoglobulin isotypes expressed.

\section{MATERIAL AND METHODS}

\section{Reagents}

All chemicals, except where mentioned, were purchased from Sigma (St. Louis, MO). Tissue-culture media and media-supplements were purchased from Invitrogen (Carlsbad, CA).

\section{PBMC isolation}

Peripheral blood from healthy donors was obtained from the Department of Transfusion Medicine, University Hospital Olomouc. Peripheral blood mononuclear cells (PBMCs) were isolated by standard protocol described elsewhere with several modifications. Shortly, $25 \mathrm{~mL}$ of EDTA-anticoagulated blood was mixed with sterile PBS (Biosera) at 3:2 ratio. The blood was applied by overlaying on the Histopaque 1077 (Sigma) and centrifuged at 400 $\mathrm{x}$ g, RT for $30 \mathrm{~min}$. The obtained PBMCs were washed twice with PBS for 20 min at RT using centrifugation with $\mathrm{RCF}=200 \times \mathrm{g}$.

\section{IL-6 stimulation of PBMC}

PBMC were transferred to complete growth medium (RPMI 1640, 10\% FBS, 1\% PenStrep) with IL-6 at concentration $10 \mathrm{ng} / \mathrm{mL}$ and incubated for 7 days at $37^{\circ} \mathrm{C}$, $5 \% \mathrm{CO}_{2}$.

\section{Cell staining for $\mathrm{FC}$ analysis}

Isolated PBMCs were stained in three steps: cell surface molecules and antibodies staining, intracellular antibodies staining, and at the end hybridization with DNA probes. Surface staining was performed after blocking the cells with $10 \%$ heat inactivated human serum in PBS (Biosera, Nuaille, France) for $10 \mathrm{~min}$ at RT. Surface molecules were labeled using selected of following mAbs: AntiCD19-PE, Anti-CD19-eFluor780, Anti-CD19-eFluor610 Anti-CD27-PE-Cy7, Anti-CD38-PE-Cy5, Anti-CD138PE-Cy7, Anti-IgM-FITC, Anti-IgD-FITC, Anti- $\beta 1$ integrin-PE, Anti- $\beta 7$ integrin-PE-Cy7, Anti-CD62L-PE-Cy5, Anti-CCR7-PE-Cy7, Anti-CCR9-PE (e-Bioscience, San Diego, CA), Anti-CD27-APC-H7, Anti-CCR5-PE-Cy5, Anti-IgG-PE-Cy5, Anti-CCR10-PE, Anti- $\alpha 4$ integrin-PECy5 (BD Biosciences, San Jose, CA), Anti-IgA-biotin, Anti-IgG-biotin (Jackson ImmunoResearch, West Grove, PA). In addition, Streptavidin-FITC (Southern Biotech, Birmingham, AL), Streptavidin-TRITC (Southern Biotech, Birmingham, AL), Streptavidin - Pacific Orange
(ThermoFisher Scientific, Waltham, MA) was used in case of biotin-labeled mAb. Viability was analyzed by Fixable Viability Dye-eFluor780 and Fixable Viability Dye-eFluor450 (e-Bioscience, San Diego, CA). All mAbs were diluted in PBS $+10 \%$ FBS and PBMCs were stained by different combinations of above antibodies for $20 \mathrm{~min}$ in the dark at RT. After washing, cells were fixed by $4 \%$ paraformaldehyde (EMS, Hatfield, PA) for $10 \mathrm{~min}$ at RT, and permeabilized with $0.5 \%$ Tween 20 (Serva, Heidelberg, Germany) in PBS for $10 \mathrm{~min}$ at RT. If required, permeabilized cells were stained for intracellular immunoglobulins using Anti-IgA-biotin, Anti-IgG-biotin and Streptavidin-FITC diluted in PBS $+0.25 \%$ Tween 20 $+5 \%$ FBS. Here, cells were incubated in the dark for 30 min at RT. Fluorophores used for staining were selected based on their stability at higher temperatures and higher salt concentrations used in subsequent hybridization procedure.

In situ hybridization was performed as follow: mAbstained cells were washed in adapting buffer containing formamide (31.25 mM NaCl, $6.25 \mathrm{mM} \mathrm{Na}$ EDTA, 62.5 $\mathrm{mM}$ Tris- $\mathrm{HCl} \mathrm{pH} 7.5$ and $37.5 \%$ formamide) and then incubated with EBER-1-specific hybridization DNA probes diluted in hybridization solution (10\% Dextran sulfate, 10 $\mathrm{mM} \mathrm{NaCl}, 30 \%$ formamide, $0.1 \%$ Sodium pyrophosphate, $0.2 \%$ polyvinylpyrrolidone, $5 \mathrm{mM} \mathrm{Na} 2$ EDTA, and $50 \mathrm{mM}$ TRIS-HCl, $\mathrm{pH} 7.5$ ) at $42{ }^{\circ} \mathrm{C}$ for $1 \mathrm{~h}$ in the dark.

Three independent EBER-1 probes were used for hybridization. Probes were synthesized as conjugated either with Cy5 or Cy3 (Generi Biotech, Hradec Kralove, Czech Republic), based on antibodies used in parallel for staining. The sequences are as follows:

\section{5'-AAACATGCGGACCACCAGCTGGTAC-3', 5'-AAGACGGCAGAAAGCAGAGTCTGGG-3', 5'-AAACCTCTAGGGCAGCGTAGGTCCT-3'"}

After the hybridization, cells were washed using $0.5 \%$ Tween 20 in PBS at $42{ }^{\circ} \mathrm{C}$ for 10 min, centrifuged, and subsequently washed for $30 \mathrm{~min}$ at the same conditions. Cells were subsequently used for flow cytometry analyses.

\section{Flow cytometry analysis}

Two different instruments were used for FACS analysis. The Canto II cytometer (BD Biosciences) equipped with blue $(488 \mathrm{~nm})$ and red $(633 \mathrm{~nm})$ laser and DIVA software and the SONY Spectral Analyzer (SONY Biotechnologies) equipped with blue $(488 \mathrm{~nm})$ and violet $(405 \mathrm{~nm})$ laser and SP6800 software. More detailed analyses were performed by FlowJo software (Tree Star Inc., Ashland, OR).

\section{Statistics}

Statistical analysis was performed utilizing one-way ANOVA model used for multiple group comparisons with Tukey's post-hoc test. All statistical analyses were done by GraphPad Prism v.5 software (GraphPad Software, La Jolla, CA). 


\section{RESULTS}

Phenotypes and immunoglobulin isotypes distribution on EBV infected B-cells

EBV-infection of B cells was detected by EBV-specific DNA probes EBER, conjugated with cy3 or cy5 fluorophores. The expression of selected surface and intracellular receptors or immunoglobulins was analyzed for individual cell together with in situ hybridization with EBER to distinguish subsets of EBV-infected and uninfected B cells by flow cytometry.

Three different groups - naïve and memory B cells and plasmablasts/plasma cells were identified by CD27, CD 38, and CD138 surface markers. CD $19^{+}$CD27 dim CD38 ${ }^{\text {dim }}$ cells represent naïve $\mathrm{B}$ cells; $\mathrm{CD} 19^{+} \mathrm{CD} 27^{+}$represent memory B cells, and $\mathrm{CD} 19^{\text {dim- }} \mathrm{CD} 27^{++}$, CD $38^{+}$represent plasmablasts/plasma cells (PB/PC). Plasma cells, in addition to $\mathrm{PB}$ are $\mathrm{CD} 138^{+}$, but in healthy individuals $\mathrm{PC}$ are almost absent in peripheral blood ${ }^{11,12}$.

PBMC were stained for CD19, CD27, CD38, and CD138 using specific antibodies and for EBER using specific DNA probe. Cells were analyzed by flow cytometry. Data are means \pm SD. Multiple groups were analyzed using one-way ANOVA followed by Tukey's post-hoc test, *** $P<0.001$

Although the total number of EBV-infected (EBER $\left.{ }^{\text {pos }}\right)$ $\mathrm{CD} 19^{+}$cells in peripheral blood is very low $-0.03 \%$ of total $\mathrm{CD} 19^{+}$cells, the distribution of the phenotype within EBV-infected cells or EBV-negative cells is significantly distinct (Fig. 1). In the group of EBV-negative cells the naïve $B$ cells population dominates followed by memory $\mathrm{B}$ cells. In contrast, in the population of EBV-infected cells, memory and $\mathrm{PB} / \mathrm{PC}$ dominates whereas naïve $\mathrm{B}$ cells represent minority.

Analysis of surface immunoglobulin expression on CD $19^{+}$cells (Fig. 2) confirmed substantial differences between uninfected and EBV-infected cells. In uninfected peripheral blood B cell population, surface $\operatorname{IgM}^{+}$and
$\mathrm{IgD}^{+}$cells dominate, followed by surface $\operatorname{IgG}^{+}$and $\operatorname{IgA}^{+}$ (Fig. 2A). In contrast, in the population of EBV-infected $\mathrm{B}$ cells, less dominant majority represent $\operatorname{IgM}^{+}$, followed by $\mathrm{IgG}^{+}$and $\mathrm{IgA}^{+}$(Fig. 2B). Negligible number of EBVpositive cells were $\operatorname{IgD}^{+}$. If we analyzed percentage of EBV-positive cells for individual surface immunoglobulin (sIg) isotype positive population ( $\operatorname{sgA}$, sIgG, sIgM, or sIgD), the highest percentage of EBV positivity was identified for surface $\mathrm{IgA}^{+} \mathrm{B}$ cells, followed by $\mathrm{IgG}^{+}$and $\mathrm{IgM}^{+}$ (Fig. 2C). This corresponds to previously published data obtained by PCR analysis of PBMC (ref. ${ }^{13}$ ). Furthermore, the low percentage of EBER ${ }^{\text {pos }} \operatorname{IgD}^{+} \mathrm{B}$ cells (Fig. 2B) indicates that $\mathrm{EBER}^{\text {pos }} \mathrm{IgM}^{+} \mathrm{B}$ cell are not $\mathrm{IgD}^{+}$and thus are not naïve but rather memory $B$ cells. Naïve $B$ cells are considered to be double positive for $\operatorname{IgM}^{+}+\operatorname{IgD}^{+}$(ref. ${ }^{14,15}$ ). Furthermore memory B cells were $\mathrm{CD} 27^{+}$whereas naïve $B$ cells were CD27 dim (data not shown) in accordance with general literature ${ }^{16,17}$.

PBMC were stained with fluorophore-labeled antibodies specific to CD19 and surface immunoglobulins of $\operatorname{IgA}, \operatorname{IgG}, \operatorname{IgM}$, and $\operatorname{IgD}$ isotype and hybridized with EBER DNA probe specific to EBV-encoded small RNAs. Cells were analyzed on flow cytometry. Data are means \pm SD. Multiple groups were analyzed using one-way ANOVA followed by Tukey's post-hoc test, *** $P<0.001$, * $P<0.05$.

\section{EBER positive $\mathrm{PB} / \mathrm{PC}$ are mainly intracellularly positive for IgA}

Results presented in the (Fig. 1) indicated that half of the EBER ${ }^{\text {pos }} \mathrm{CD}_{19}{ }^{+}$cells are memory and half of them are $\mathrm{PB} / \mathrm{PC}$. Despite the fact that the percentage of intracellularly positive cells in PBMC is very low - approx. $1 \%$ (Fig. 1,3A), the proportion of individual immunoglobulin isotype positive cells differs for EBER ${ }^{\text {pos }}$ and EBER ${ }^{\text {neg }}$.. In $\mathrm{EBER}^{\text {neg }} \mathrm{PB} / \mathrm{PC}$ the most abundant population of intracellular immunoglobulin (iIg) positive cells are $\mathrm{IIgM}^{+}$, followed by $\operatorname{iIgA}^{+}$and $\operatorname{iIgG}^{+}$(Fig. 3A) In contrast, in the

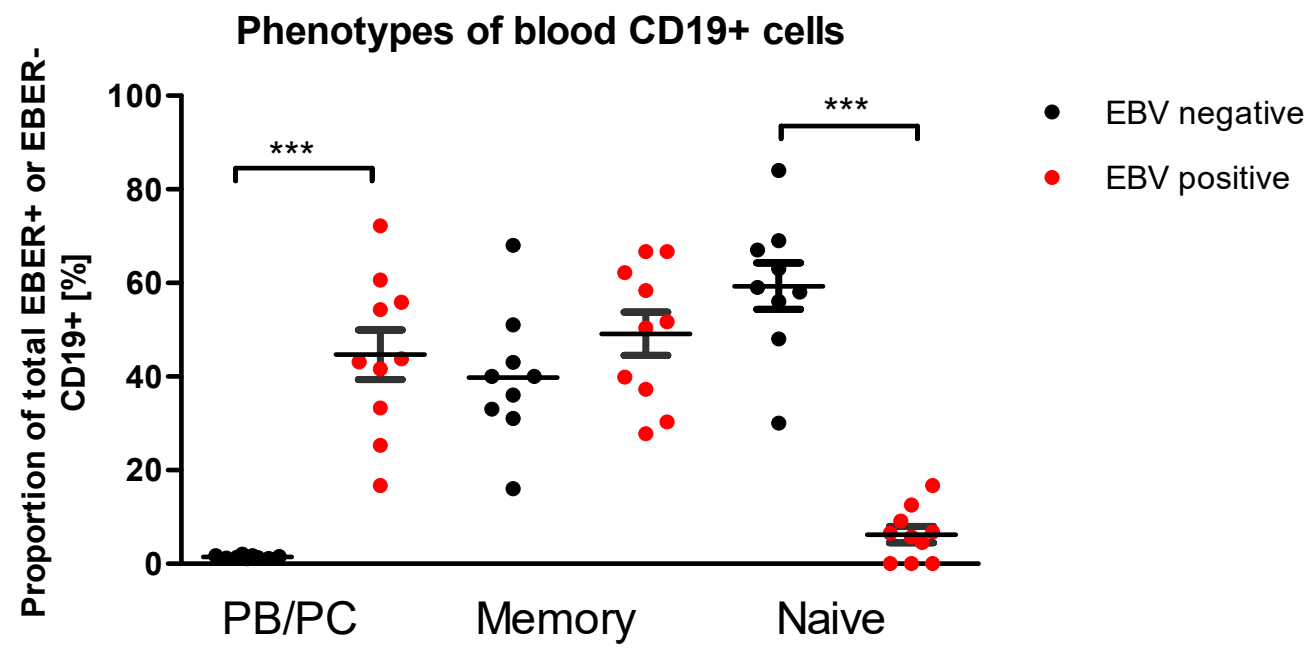

Fig. 1. Proportion of naïve and memory $B$ cells and $P B / P C$ in peripheral blood are different for EBV-infected and uninfected cells. 
population of EBER ${ }^{\text {pos }} \mathrm{PB} / \mathrm{PC}$ the $\mathrm{iIg} \mathrm{A}^{+}$population significantly dominates over others iIg isotypes (Fig. 3B).

PBMC were stained with fluorophore-labeled antibodies against surface CD19, CD27, CD38 and intracellular iIgA, iIgG, iIgM followed by in situ hybridization with EBER DNA probe specific to EBV-encoded small RNAs. A) Population of EBER ${ }^{\text {neg }} \mathrm{CD} 19^{\text {dim- }} \mathrm{CD} 27^{++}, \mathrm{CD} 38^{+}$representing $\mathrm{PB} / \mathrm{PC}$ was analyzed for distribution of individual iIg cells. B) Population of EBER ${ }^{\text {pos }} \mathrm{PB} / \mathrm{PC}$ was analyzed for distribution of individual iIg cells. Data are means \pm SD. Multiple groups were analyzed using oneway ANOVA followed by Tukey's post-hoc test, * $P<0.05$; ** $P<0.01$; *** $P<0.001$.

EBV-infected B cells keep expression of integrin $\alpha 4 \beta 7$ but reduce the expression of $\alpha 4 \beta 1$ leading to their preferential targeting to gut mucosa

Because peripheral blood EBER ${ }^{\text {pos }} \mathrm{CD} 19^{+}$cells exhibit dominantly memory or PB/PC phenotype, we analyzed migration destination of such cells by analyzing surface integrin and chemokine expression.

Analysis of $\alpha 4 \beta 1$ positive or $\alpha 4 \beta 7$ positive cells, and L-selectin positive cells from $\mathrm{CD} 19^{+}$population is shown in Fig. 4A.

PBMC were stained with fluorophore-labeled antibodies against CD19, sIgG, sIgA, $\alpha 4 \beta 7, \alpha 4 \beta 1$, L-selectin, and hybridized with EBER DNA probe specific to EBVencoded small RNAs. A) Expression of $\alpha 4 \beta 7, \alpha 4 \beta 1$, and L-selectin in population of all B cells to EBV infection $\left(\right.$ EBER $^{\text {neg }}$ cells are in black, EBER ${ }^{\text {pos }}$ cells are in red).
Analogous analysis was performed for $\mathrm{B}$ ) $\operatorname{sIgA}^{+}$and $\mathrm{C}$ ) for $\mathrm{sIgG}$ cells. Data are means $\pm \mathrm{SD}$. Multiple groups were analyzed using one-way ANOVA followed by Tukey's posthoc test, ${ }^{*} P<0.05 ; * * * P<0.001$.

The percentage of $\alpha 4 \beta 1^{+}$and $\alpha 4 \beta 7^{+}$B cells differ significantly between EBV-positive and negative populations (Fig. 4A) indicating that EBV affects substantially migratory behavior of peripheral blood B cells. Although EBV-negative B cells are dominantly $\alpha 4 \beta 7^{+}$, typical for gut homing $\mathrm{PB}, \mathrm{EBV}$-positive population contains significantly less $\alpha 4 \beta 7^{+}$cells. Even more, EBV positivity is associated with almost total loss of $\alpha 4 \beta 1^{+}$cells, whereas EBV negative B cells population contains about $15 \%$ of $\alpha 4 \beta 1^{+}$cells. Furthermore, we determined integrin expression on $\mathrm{sIgA}^{+}$or $\mathrm{sIgG}^{+}$cells relative to EBV positivity (Fig. 4B,C). In the case of $\operatorname{sig} \mathrm{A}^{+}$population, EBV positivity is associated with insignificant increase in $\alpha 4 \beta 7^{+}$ cells but total absence of $\alpha 4 \beta 1^{+}$cells which implicates limited migration of EBV-infected peripheral blood $\mathrm{IgA}^{+}$ cells to upper respiratory tract, bronchus, lungs, tonsils, and Waldeyer's ring ${ }^{18-20}$. Less pronounced changes were detected for $\mathrm{sIgG}^{+}$cells. Observed differences between EBV-positive and negative cells for integrin expression on total B cell population, $\operatorname{sIgA}^{+}$, and $\operatorname{sIgG}^{+}$cells (Fig. 4A versus Fig. 4B,C) indicate involvement of sIgM cells especially in EBV-negative B cells population.

When analyzing $B$ cells for L-selectin relative to EBV infection, no significant difference was observed between EBV -positive and -negative B cells with mean $80 \%$ of positive B cells.
A

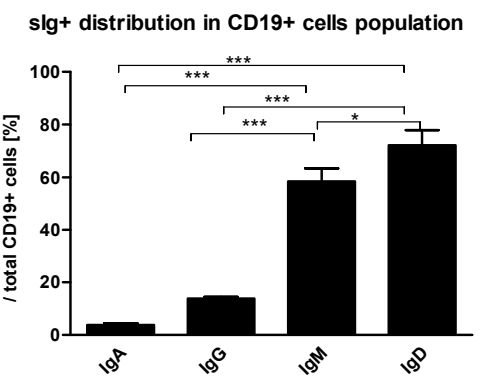

B

slg+ EBER+ distribution in CD19+ population

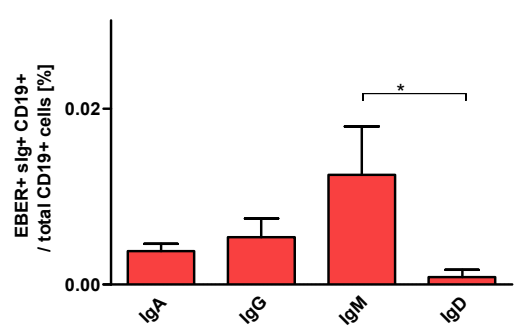

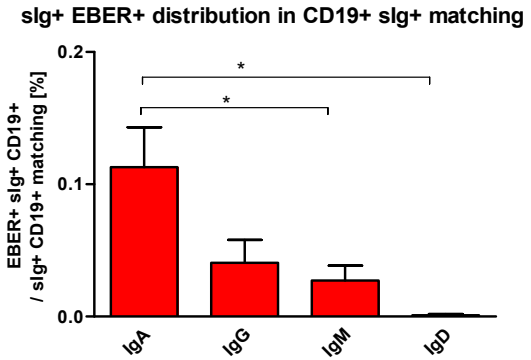

Fig. 2. Differences in surface immunoglobulin expression on $\mathrm{CD} 19^{+}$cells uninfected and infected with EBV.

A

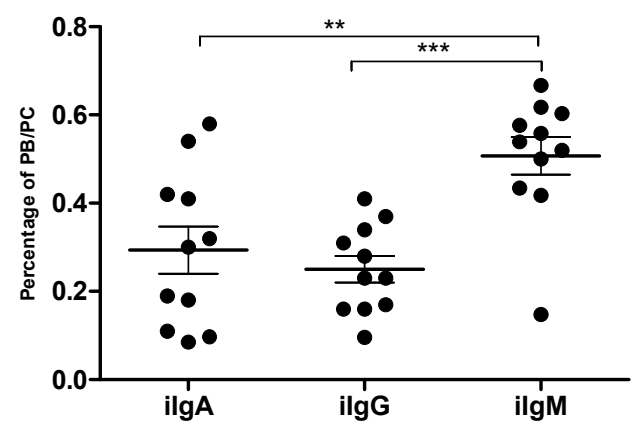

B

ilg isotypes of EBER ${ }^{\text {pos }} \mathrm{PB} / \mathrm{PC}$ in PBMC

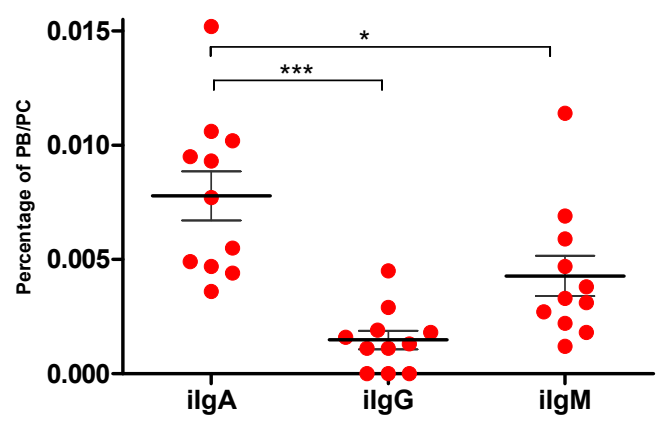

Fig. 3. $E B E R^{\text {pos }} \mathrm{PB} / \mathrm{PC}$ cells are predominantly of $i \operatorname{Ig} \mathrm{A}^{+}$. 


\section{A}

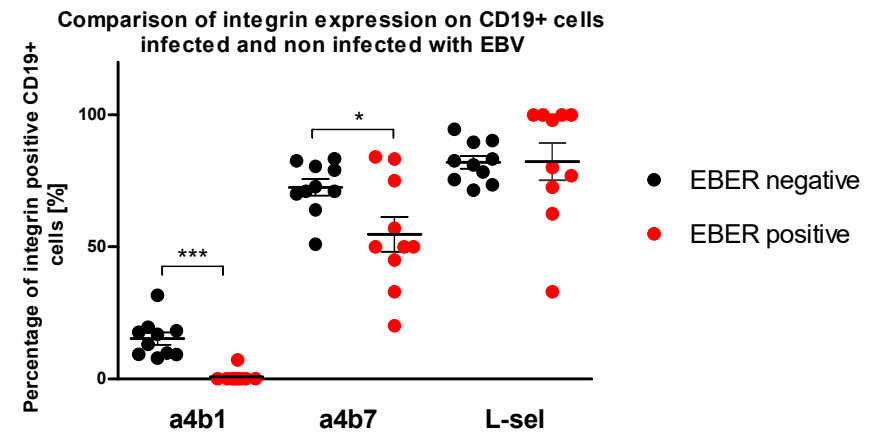

B

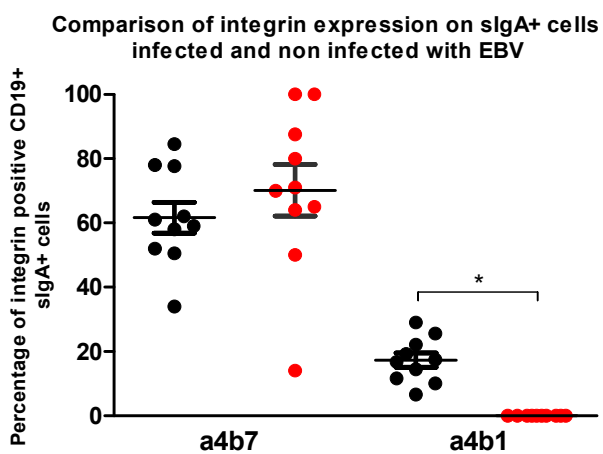

C

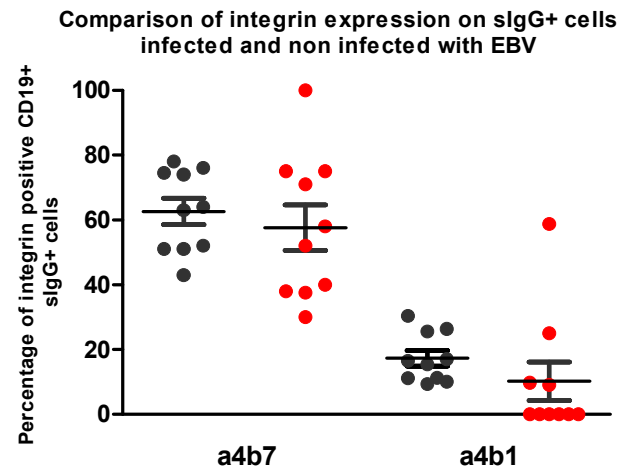

Fig. 4. Integrin molecules expression in total $\mathrm{B}$-, $\operatorname{sIg} \mathrm{A}^{+}$- and $\mathrm{sIgG}^{+}$- cells relative to EBV infection.

\section{Chemokine receptor expression}

In addition to integrins and L-selectin, B cells were analyzed for the expression of CCR5, CCR7, CCR9, CCR10 chemokine receptors depending to EBV positivity and negativity. EBV-positive B cells contained significantly higher proportion of $\mathrm{CCR}^{+}$and $\mathrm{CCR}^{+}$cells in comparison to EBV-negative cells. The changes of the percentage of $\mathrm{CCR}^{+}$and $\mathrm{CCR} 10^{+}$cells relative to $\mathrm{EBV}$ infection was only modest and not significant (Fig. 5).

PBMC were stained using fluorophore-labeled antibodies specific to CD19, CCR5, CCR7, CCR9, and CCR10 and hybridized with EBER DNA probe specific to EBV-encoded small RNAs. Cells were analyzed by flow cytometry. EBER ${ }^{\text {pos }}$ cells are in red, EBER ${ }^{\text {neg }}$ cells are in black. Data are means \pm SD. Multiple groups were analyzed using one-way ANOVA followed by Tukey's post-hoc test, * $P<0.05 ; * * * P<0.001$.

\section{B cells response to IL-6 in EBV-positive and EBV-negative} cells

IL-6 stimulates predominantly CD $19^{+} \mathrm{CD} 27^{++} \mathrm{CD} 38^{+}$ CD $138^{+}$with low level of surface immunoglobulin ( sIg $^{\mathrm{dim}}$ ) and high level of intracellular immunoglobulin (iIg $\left.{ }^{+}\right)$expression corresponding to plasmablasts and/or plasma cells (PB/PC) (data not shown). After IL-6 stimulation, the population of $\mathrm{EBER}^{+} \mathrm{B}$ cells is substantially reduced (Fig. 6A) indicating that in healthy subjects IL-6 stimulates preferentially EBV-negative cells of which
IgA-producing plasma cells are the most effective IL-6 responders (Fig. 6B). When analyzing $\mathrm{EBER}^{+}$subpopulation of $\mathrm{PB} / \mathrm{PC}$ after IL-6 exposure, variable reduction was observed for individual isotype (i $\operatorname{IgA}, \mathrm{i} \operatorname{IgG}$, $\mathrm{igM}$ ) positive $\mathrm{PB} / \mathrm{PC}$. The most substantial reduction was observed for iIgM, followed by IgG and IgA (Fig. 6C). Thus IgAproducing EBV-positive $\mathrm{PB} / \mathrm{PC}$ are the only subpopulation of EBV-infected PB/PC which after IL-6 stimulation is able to contribute to immunoglobulin production in addition to dominant EBV-negative IgA producing PB/PC.

PBMC were stimulated with $10 \mathrm{ng} / \mathrm{mL}$ IL-6 for 7 days and thereafter stained using fluorophore-labeled antibodies specific to CD19, CD27, CD38, CD138, surface immunoglobulin (sIg) and intracellular immunoglobulin (iIg), and hybridized with EBER DNA probe specific to EBV-encoded small RNAs. Cells were analyzed by flow cytometry. EBER ${ }^{\text {pos }}$ cells are in red, EBER ${ }^{\text {neg }}$ cells are in black. Data are means \pm SD. Multiple groups were analyzed using one-way ANOVA followed by Tukey's post-hoc test, * $P<0.05$; * $P<0.01 ; * * * P<0.001$.

\section{DISCUSSION}

Our results showed a substantial discrepancies in migratory behavior of Epstein-Barr virus infected B cells in peripheral blood. Using multiparametric flow cytometry when intracellular and extracellular antigens are detected 


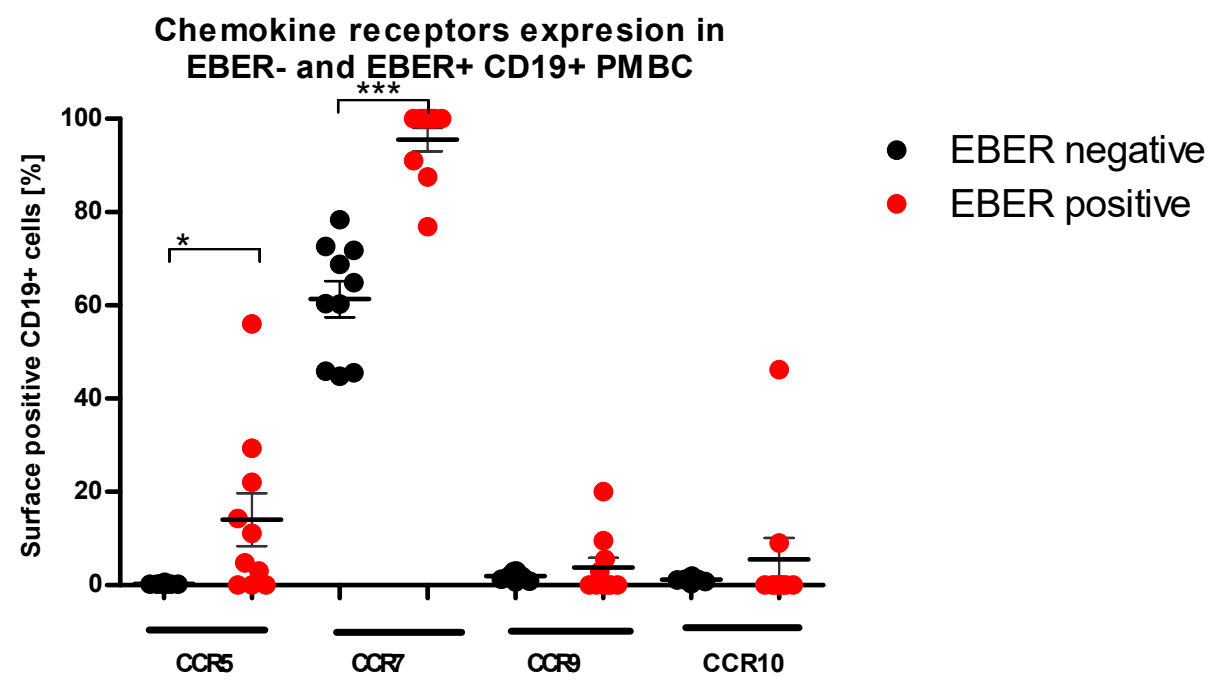

Fig. 5. The expression of chemokine receptors on B cell relative to EBV infection.

together with intracellular EBV-encoded small RNAs we are able to analyze properties of individual B cells subpopulation. Beside maturation and isotype distribution in EBV-positive and -negative B cells we could analyze other characteristics such as integrin and chemokine receptors expression as a marker of trafficking destiny.

All previously published analyses of EBV-infected cells were based on pool of cells isolated by specific phenotype (naïve cells, memory cells, plasmablast, or immunoglobulin isotype $\left(\mathrm{IgA}^{+}, \mathrm{IgG}^{+}, \mathrm{IgM}^{+}\right)$followed by analysis of $\mathrm{EBV}$ nucleic acid copies within cells or after cell stimulation in the culture supernatants ${ }^{21-23}$. Other often used approach focuses on describing of particular changes in cells that have been immortalized by EBV (ref. ${ }^{24,25}$ ). Different chemokine receptors as well as integrins expression were described $^{26,27}$.

Another very frequently used approach for EBV detection uses fixed embedded tissues, that are immunohistochemically characterized using in situ hybridization with EBV-specific PNA probes ${ }^{28-30}$. Nevertheless, none of such methods enables a broad and specific characteristic of individual EBV-infected cells at various maturation stage, expressing various migratory molecules and various antibody isotype intracellularly or on their surface in one assay.

Our results describe the characteristics of peripheral blood EBV-infected cells in healthy individuals. We show that EBV-positive B cells are predominantly $\operatorname{IgM}^{+}$(and less $\mathrm{IgG}^{+}$) memory B cells or $\operatorname{IgA}^{+}$(and less $\operatorname{IgM}^{+}$) plasmablasts/plasma cells and minority of naïve $B$ cells. These results correspond with the high percentage of $\operatorname{IgM}^{+} \mathrm{B}$ cells in peripheral blood. Nevertheless, applied on percentage of each $\mathrm{SIg}^{+}$population, it could be summarized, that EBV preferentially infects $\operatorname{sIg}^{+} \mathrm{B}$ cells (Fig. 2C).

Moreover our results show that the trafficking characteristics of EBER ${ }^{\text {pos }} B$ cells are distinct from EBER ${ }^{\text {neg }}$ $\mathrm{B}$ cells. Maximal differences were detected for $\alpha 4 \beta 1$ fol- lowed by $\alpha 4 \beta 7$ and CCR7 and weakest differences were detected for CCR5. Although EBER ${ }^{\text {neg }} \mathrm{B}$ cells from peripheral blood are mainly naïve $B$ cells targeted to peripheral lymph nodes by $\alpha 4 \beta 7$, L-selectin and partially by CCR7 (Fig. 4A, Fig. 5), EBER ${ }^{\text {pos }}$ B cells are mainly of memory and $\mathrm{PB} / \mathrm{PC}$ subtypes, expressing less frequently $\alpha 4 \beta 7$, but, in absolute majority of $\mathrm{EBER}^{+}$cell CCR7. Thus, it could be hypothesized that one of dominant destination for $\mathrm{EBER}^{+}$cells are peripheral lymph nodes including spleen $^{31-35}$, in other words, it could be hypothesized that EBV infection of B cells actively narrows their migration through body compartments. The only EBER ${ }^{\text {pos }} \mathrm{B}$ cell population which is not reduced in $\alpha 4 \beta 7$ expression are surface $\mathrm{IgA}^{+}$cells (Fig. 4B) indicating that EBER ${ }^{+} \mathrm{IgA}^{+}$ cells could reach more easily peripheral lymph nodes and spleen than their healthy counterparts.

The EBER ${ }^{\text {pos }} \mathrm{PB} / \mathrm{PC}$ subpopulations expressing $\alpha 4 \beta 7$, CCR9, and CCR10 are expected migratory cells destined to places of antibody secretion, such as gut lamina propria or nasal cavity. In contrast to healthy B cells of which almost none are CCR9 and CCR10 positive (Fig. 5), at least some EBER ${ }^{\text {pos }} \mathrm{B}$ cells express CCR9 and CCR10 which could indicate that EBV infection enhances migration to gut or nasal mucosa. EBER ${ }^{\text {pos }} \mathrm{IgG}^{+} \mathrm{B}$ cells express $\alpha 4 \beta 7$ and $10 \%$ also $\alpha 4 \beta 1$, of which the second would target them to bone marrow ${ }^{36,37}$.

The differences in EBER ${ }^{\text {pos }} \mathrm{B}$ cells and EBER ${ }^{\text {neg }} \mathrm{B}$ cells in maturation stage, homing-migration molecules and immunoglobulin isotype expression in peripheral blood of healthy individuals clearly shows that infection of B cells by EBV has dramatic effect on their function. Although generally EBV-infected B cells represent only minor subpopulation of total B cell pool, due to their atypical behavior, they could contribute to development of immune abnormalities such as autoimmune diseases or some tumors, as was proposed shortly after description of EBV biology ${ }^{23,38}$. 
A

IL-6 does not stimulate EBER+ CD19+ cells

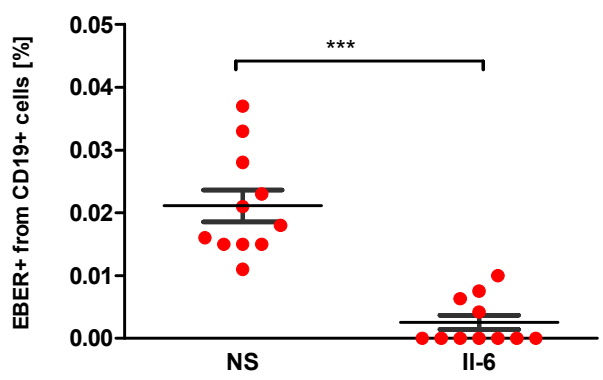

\section{B} IL-6 stimulates uninfected ilgA+ PB/PC

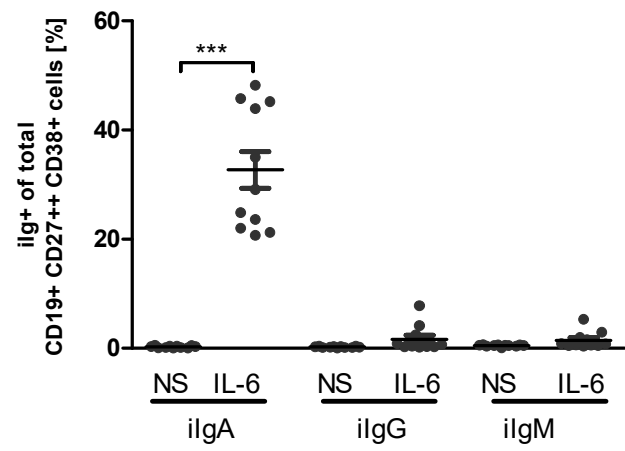

Fig. 6. Peripheral blood B cells response to IL-6.

\section{CONCLUSION}

Using multi-parameter flow cytometry analysis it is possible to measure simultaneously several characteristics on individual cell including surface receptor, intracellular DNA or RNA molecules, and intracellular protein expression.

We found that the trafficking characteristics of EBVinfected B cells are distinct for EBV-negative B cells with most dominant differences detected for $\alpha 4 \beta 1$ and $\alpha 4 \beta 7$ integrins and CCR5 and CCR7 chemokine receptors. EBV-infected cells are predominantly memory $\operatorname{IgM}^{+}$B cells or plasmablasts/plasma cells positive for IgA and less cells positive for IgM. In comparison to uninfected B cells, EBV-positive B cells contain smaller population of cells expressing $\alpha 4 \beta 7$ and almost no cells expressing $\alpha 4 \beta 1$. EBV-infected B cells contained significantly higher proportion of $\mathrm{CCR}^{+}$and $\mathrm{CCR} 7^{+}$cells in comparison to EBV-negative cells. In vitro exposure of blood mononuclear cells to pro-inflammatory cytokine IL-6 reduces substantially the population of EBV-positive B cell of IgM ${ }^{+}$ and $\mathrm{IgG}^{+}$subsets.

Although EBV-infected B cells represent only a minor subpopulation of all $\mathrm{B}$ cells in peripheral blood, their atypical functions could contribute in predisposed person to development of diseases of autoimmune or malignant nature.
Acknowledgments: The research was supported by Czech Health Research Council 15-33686A and conceptual development of research organization grant (MHCZ-DRO, FNO1, 00098892), Ministry of Health, Czech Republic and by Ministry of School, Youth, and Sport, Czech Republic grant CZ.02.1.01/0.0/0.0/16_025/0007397.

Author contributions: JM, MR: designed the study; KZ, MR:. wrote the manuscript; KZ: performed the flow cytometry analyses; PK, KK: processed the patient's blood specimens; JZ, KM, KV: collected patient's clinical data and collected the blood samples; PH, HTH: interpreted experimental data.

Conflict of interest statement: The authors state that there are no conflicts of interest regarding the publication of this article.

\section{REFERENCES}

1. Baumforth KR, Young LS, Flavell KJ, Constandinou C, Murray PG. The Epstein-Barr virus and its association with human cancers. Mol Pathol 1999;52(6):307-22.

2. Ascherio A, Munger KL. EBV and Autoimmunity. Curr Top Microbiol Immunol 2015;390(Pt 1):365-85.

3. Capone G, Fasano C, Lucchese G, Calabro M, Kanduc D. EBVAssociated Cancer and Autoimmunity: Searching for Therapies. Vaccines (Basel) 2015;3(1):74-89.

4. Crawford DH. Biology and disease associations of Epstein-Barr virus. Philos Trans R Soc Lond B Biol Sci 2001;356(1408):461-73. 
5. Draborg AH, Duus K, Houen G. Epstein-Barr virus in systemic autoimmune diseases. Clin Dev Immunol 2013;2013:535738. doi: $10.1155 / 2013 / 535738$

6. Murray PG, Billingham LJ, Hassan HT, Flavell JR, Nelson PN, Scott K, Reynolds G, Constandinou CM, Kerr DJ, Devey EC, Crocker J, Young LS. Effect of Epstein-Barr virus infection on response to chemotherapy and survival in Hodgkin's disease. Blood 1999;94(2):442-7.

7. Morandi E, Jagessar SA, T Hart BA, Gran B. EBV Infection Empowers Human B Cells for Autoimmunity: Role of Autophagy and Relevance to Multiple Sclerosis. J Immunol 2017;199(2):435-48.

8. Kishimoto T. Factors affecting B-cell growth and differentiation. Annu Rev Immunol 1985;3:133-57.

9. Klashman DJ, Martin RA, Martinez-Maza O, Stevens RH. In vitro regulation of B cell differentiation by interleukin- 6 and soluble CD23 in systemic lupus erythematosus B cell subpopulations and antigeninduced normal B cells. Arthritis Rheum 1991;34(3):276-86.

10. Dienz O, Eaton SM, Bond JP, Neveu W, Moquin D, Noubade R, Briso EM, Charland C, Leonard WJ, Ciliberto G, Teuscher C, Haynes $\mathrm{L}$, Rincon $\mathrm{M}$. The induction of antibody production by IL- 6 is in directly mediated by IL-21 produced by CD4+ T cells. J Exp Med 2009;206(1):69-78.

11. Fakan F, Boudova L, Hejda C. [Syndecan-1 (CD138): an immunohistochemical marker of plasma cell tumors]. Cesk Patol 2002;38(1):33-6.

12. O'connell FP, Pinkus JL, Pinkus GS. CD138 (syndecan-1), a plasma cell marker immunohistochemical profile in hematopoietic and nonhematopoietic neoplasms. Am J Clin Pathol 2004;121(2):254-63.

13. Ehlin-Henriksson B, Zou JZ, Klein G, Ernberg I. Epstein-Barr virus genomes are found predominantly in IgA-positive B cells in the blood of healthy carriers. Int J Cancer 1999;83(1):50-4.

14. Duty JA, Szodoray P, Zheng NY, Koelsch KA, Zhang Q, Swiatkowski M, Mathias M, Garman L, Helms C, Nakken B, Smith K, Farris AD Wilson PC. Functional anergy in a subpopulation of naive $B$ cells from healthy humans that express autoreactive immunoglobulin receptors. J Exp Med 2009;206(1):139-51.

15. Koelsch K, Zheng NY, Zhang Q, Duty A, Helms C, Mathias MD, Jared M, Smith K, Capra JD, Wilson PC. Mature B cells class switched to IgD are autoreactive in healthy individuals. J Clin Invest 2007;117(6):1558 65.

16. Kaminski DA, Wei C, Qian Y, Rosenberg AF, Sanz I. Advances in human B cell phenotypic profiling. Front Immunol 2012;3:302.

17. Weller S, Braun MC, Tan BK, Rosenwald A, Cordier C, Conley ME, Plebani A, Kumararatne DS, Bonnet D, Tournilhac O, Tchernia G, Steiniger B, Staudt LM, Casanova JL, Reynaud CA, Weill JC. Human blood lgM "memory" $B$ cells are circulating splenic marginal zone $B$ cells harboring a prediversified immunoglobulin repertoire. Blood 2004;104(12):3647-54

18. Pakkanen SH, Kantele JM, Moldoveanu Z, Hedges S, Hakkinen M, Mestecky J, Kantele A. Expression of homing receptors on IgA and IgA2 plasmablasts in blood reflects differential distribution of $\lg A 1$ and $\lg A 2$ in various body fluids. Clin Vaccine Immunol 2010;17(3):393-401.

19. Johansen FE, Baekkevold ES, Carlsen HS, Farstad IN, Soler D Brandtzaeg P. Regional induction of adhesion molecules and chemokine receptors explains disparate homing of human B cells to systemic and mucosal effector sites: dispersion from tonsils. Blood 2005;106(2):593-600.

20. Brandtzaeg P. (2015). The mucosal B cell system. In J. Mestecky, W. Strober, M. W. Russel, B. L. Kelsall, H. Cheroutre \& B. N. Lambrecht (Eds.), Mucosal immunology (Fourth edition. ed., Vol. I, pp. 623-81). Amsterdam: Elsevier/AP, Academic Press is an imprint of Elsevier.

21. Al Tabaa Y, Tuaillon E, Bollore K, Foulongne V, Petitjean G, Seigneurin JM, Duperray C, Desgranges C, Vendrell JP. Functional Epstein-Barr virus reservoir in plasma cells derived from infected peripheral blood memory B cells. Blood 2009;113(3):604-11.
22. Richard Y, Amiel C, Jeantils V, Mestivier D, Portier A, Dhello G, Feuillard J, Creidy R, Nicolas JC, Raphael M. Changes in blood B cell phenotypes and Epstein-Barr virus load in chronically human immunodeficiency virus-infected patients before and after antiretroviral therapy. J Infect Dis 2010;202(9):1424-34

23. Nagata K, Kumata K, Nakayama Y, Satoh $Y$, Sugihara H, Hara S Matsushita M, Kuwamoto S, Kato M, Murakami I, Hayashi K. Epstein-Barr Virus Lytic Reactivation Activates B Cells Polyclonally and Induces Activation-Induced Cytidine Deaminase Expression: A Mechanism Underlying Autoimmunity and Its Contribution to Graves' Disease. Viral Immunol 2017;30(3):240-9.

24. Miller G. Immortalization of human lymphocytes by Epstein-Barr virus. Yale J Biol Med 1982;55(3-4):305-10.

25. Tosato G, Cohen Jl. Generation of Epstein-Barr Virus (EBV)immortalized B cell lines. Curr Protoc Immunol 2007; Chapter 7:Unit 7.22. doi: $10.1002 / 0471142735$.im0722s76

26. Nakayama T, Fujisawa R, Izawa D, Hieshima K, Takada K, Yoshie O. Human B cells immortalized with Epstein-Barr virus upregulate CCR6 and CCR10 and downregulate CXCR4 and CXCR5. J Virol 2002;76(6):3072-7.

27. Huang S, Stupack D, Liu A, Cheresh D, Nemerow GR. Cell growth and matrix invasion of EBV-immortalized human B lymphocytes is regulated by expression of alpha(v) integrins. Oncogene 2000;19(15):1915-23.

28. Kurth J, Hansmann ML, Rajewsky K, Kuppers R. Epstein-Barr virusinfected $B$ cells expanding in germinal centers of infectious mononucleosis patients do not participate in the germinal center reaction. Proc Natl Acad Sci U S A 2003;100(8):4730-5.

29. Mahjoub F, Shahsiah R, Ardalan FA, Iravanloo G, Sani MN, Zarei A Monajemzadeh M, Farahmand F, Mamishi S. Detection of Epstein Barr virus by chromogenic in situ hybridization in cases of extrahepatic biliary atresia. Diagn Pathol 2008;3:19.

30. Gulley ML. Molecular diagnosis of Epstein-Barr virus-related diseases. J Mol Diagn 2001;3(1):1-10.

31. Pereira JP, Kelly LM, Cyster JG. Finding the right niche: B-cell migration in the early phases of T-dependent antibody responses. Int Immunol 2010;22(6):413-9.

32. Hopken UE, Achtman AH, Kruger K, Lipp M. Distinct and overlapping roles of CXCR5 and CCR7 in B-1 cell homing and early immunity against bacterial pathogens. J Leukoc Biol 2004;76(3):709-18.

33. Cameron PU, Jones P, Gorniak M, Dunster K, Paul E, Lewin S, Woolley I, Spelman D. Splenectomy associated changes in IgM memory B cells in an adult spleen registry cohort. PLoS One 2011;6(8):e23164.

34. Kruetzmann S, Rosado MM, Weber H, Germing U, Tournilhac $\mathrm{O}$, Peter HH, Berner R, Peters A, Boehm T, Plebani A, Quinti I, Carsetti R. Human immunoglobulin $M$ memory B cells controlling Streptococcus pneumoniae infections are generated in the spleen. J Exp Med 2003;197(7):939-45.

35. Seifert M, Przekopowitz M, Taudien S, Lollies A, Ronge V, Drees B, Lindemann M, Hillen $U$, Engler $H$, Singer BB, Kuppers R. Functional capacities of human IgM memory $B$ cells in early inflammatory responses and secondary germinal center reactions. Proc Natl Acad Sci U S A 2015;112(6):E546-55.

36. Underhill GH, Minges Wols HA, Fornek JL, Witte PL, Kansas GS. IgG plasma cells display a unique spectrum of leukocyte adhesion and homing molecules. Blood 2002;99(8):2905-12.

37. Winkelmann R, Sandrock L, Porstner M, Roth E, Mathews M, Hobeika E, Reth M, Kahn ML, Schuh W, Jack HM. B cell homeostasis and plasma cell homing controlled by Kruppel-like factor 2. Proc Natl Acad Sci U S A 2011;108(2):710-5.

38. Laurence $M$, Benito-Leon J. Epstein-Barr virus and multiple sclerosis: Updating Pender's hypothesis. Mult Scler Relat Disord 2017;16:8-14. 